\title{
Single-platform, volumetric, CD45-assisted pan-leucogating flow cytometry for CD4 T lymphocytes monitoring of HIV infection according to the WHO recommendations for resource-constrained settings
}

Donato Koyalta ${ }^{1 *}$, Mohammad-Ali Jenabian$^{2}$, Ngamasra Nadjiouroum $^{3}$, Barou Djouater $^{4}$, Noël Djemadji-Oudjeil ${ }^{5}$, Angélique Ndjoyi-Mbiguino ${ }^{6}$ and Laurent Bélec ${ }^{7}$

\begin{abstract}
Background: Validation of new affordable CD4 T cell measurement technologies is crucial specifically in resourcepoor countries for antiretroviral treatment eligibility and immunologic CD4 monitoring of HIV-infected patients.

Methods: The absolute and percentage CD4 T cell counts of 258 HIV-1-infected blood samples (182 adults and 76 children), living in N'Djamena, Chad, were performed by single-platform, volumetric, CD45-assisted pan-leucogating Auto40 flow cytometer (Apogee Flow Systems Ltd, Hemel Hempstead, UK) comparing to the FACSCalibur flow cytometer as a reference method.

Results: Absolute and percentage CD4 T cell counts obtained by Auto40 and FACSCalibur of 258 HIV-1-infected blood samples were highly correlated $(r=0.99$ and $r=0.96$, respectively). The mean absolute bias and percent bias between Apogee Auto40 and FACSCalibur absolute CD4 T cell counts, were -9.4 cells/ $\mu$ with limits of agreement from -15 to 93 cells $/ \mu \mathrm{l}$, and $+2.0 \%$ with limits of agreement from -0.9 to $4.9 \%$, respectively. The mean of absolute bias and percent bias between Apogee Auto40 and FACSCalibur of CD4 percentage results were $+0.4 \%$ (95\% Cl: $-0.02-0.86$ ) with limits of agreement from -2.4 to $0.3 \%$, and $+3.0 \%$ with limits of agreement from -6.6 to $0.6 \%$, respectively. The Auto40 counting allowed to identify the majority of adults with CD4 T cells below 200 cells/ $\mu$ l (sensitivity: 89\%; specificity: 99\%) or below 350 cells/ $\mu$ (sensitivity: 94\%; specificity:98\%); and of children below 750 cells/ $\mu$ l (sensitivity: 99\%; specificity: 96\%) or below 25\% CD4+ (sensitivity: 94\%; specificity: 98\%).

Conclusion: The Auto40 analyzer is an alternative flow cytometer for CD4 T lymphocyte enumeration to be used in routine for immunological monitoring according to the current WHO recommendations in HIV-infected adults as well as children living in resource-constrained settings like Chad.
\end{abstract}

Keywords: Flow cytometry, CD4 T cell count, Pan-leucogating, CD45, Sub-Saharan Africa, Chad

\footnotetext{
* Correspondence: koyaltad@yahoo.fr

'Ministère de la Santé Publique, N'Djamena BP 407, Chad

Full list of author information is available at the end of the article
} 


\section{Background}

The HIV epidemic remains a major global public health challenge with a total of 33.4 million people living with HIV worldwide [1]. The past decade has witnessed a remarkable global effort to improve access to HIV antiretroviral therapy (ART). The current guidelines of the World Health Organization (WHO) for scaling up of ART in adults and children living in resource-limited settings [2,3], emphasize the necessity of laboratory monitoring, which is initially based on immunological assessment by the enumeration of CD4 T lymphocytes, mainly to start ART and monitor patients on ART. In addition, HIV-1 RNA load is now recommended in order to monitor treatment efficacy and early therapeutic failure in patients on ART as well as to monitor therapeutic switch $[4,5]$.

CD4 $\mathrm{T}$ lymphocytes monitoring typically relies on complex flow cytometry equipment which requires infrastructure and technical skills which are commonly unavailable at rural and remote clinics [6]. New point-ofcare (POC) CD4 technologies enable testing to be decentralized to these sites and for test results to be provided during the course of the patient visit [7]. Recent studies have demonstrated that POC CD4 T lymphocytes monitoring can significantly improve rates of ART initiation and reduce patient loss-to-follow-up, which is often high before treatment initiation $[1,8,9]$. Immediate access to CD4 $\mathrm{T}$ cells results may also enable more rapid initiation of prophylactic treatment for opportunistic infections as well as chemotherapy for prevention of mother-to-child transmission at sites where CD4 T lymphocytes levels define the prophylactic drug regimen $[10,11]$. Affordable CD4 T cell counting has gradually become possible by using simple, compact and robust low-cost new generation of POC flow cytometers operating as single-platform volumetric instruments without the use of expensive microbeads [7,12-14]. Introduced in 2005, the recently developed Auto40 flow cytometer (Apogee Flow Systems Ltd, Hemel Hempstead, UK; www.Apogeeflow.com) was originally designed for military applications [15]. The Auto40 assay is based on nolyse procedure [16], which avoids the red blood cell lysis step, thereby reducing assay variability due to changes in assay conditions (time and temperature of incubation) as well as differences in the susceptibility of cells to the lysis reagents [17]. The Auto40 analyzer uses a volumetric syringe moved by a stepper motor that draws and delivers a known sample volume. Therefore, its absolute volumetric counting allows the direct determination of the number of cells per unit of sample volume without the need for reference material such as microbeads $[13,18]$.

Due to the stability of its optical bench, the Auto40 may be used on peripheral stationary as well as mobile flow cytometry unit [15]. The Auto40 analyzer was initially intended for CD4 T cell enumeration based on primary $\mathrm{CD} 4$ gating, and has been validated for measurement of absolute CD4 $\mathrm{T}$ cell count by reference to the FACSCount system [15]. The analyzer has been recently updated for CD4 $\mathrm{T}$ cells measurement within 30 minutes, using pan-leucogating protocol with primary CD45 gating followed by secondary CD4 gating, that allows results to be obtained in a single measurement of the CD4 $\mathrm{T}$ cell count expressed both in absolute number and in percentage $[19,20]$, and therefore to address the current WHO recommendations for CD4 $\mathrm{T}$ cell measurements in children less than 5 years [2]. The initial version of Auto40 analyzer based on primary CD4 gating for CD4 $\mathrm{T}$ cell enumeration in absolute number has been evaluated positively in [15]; and the current version is based on CD45-assisted panleucogating for CD4 T cell enumeration in absolute number as well as in percentage in Cameroon $[19,20]$.

The WHO strongly recommends scientific publications of effective validation of newly introduced affordable CD4 $\mathrm{T}$ cell measurement technologies carried out in the field by several laboratories of different resourcepoor countries, and independently of manufacturers $[6,21]$. Therefore, the objective of the present study was to perform a novel and independent evaluation of the biological performances of the Auto40 analyzer in the HIV dedicated reference laboratory of the hôpital Militaire d'Instruction, located in N'Djamena, the capital city of Republic of Chad.

\section{Methods}

\section{Clinical specimens and processing}

Tripotassium ethylenediamine tetraacetate (K3-EDTA)blood samples obtained by venipuncture in Vacutainer tubes (Becton Dickinson, Franklin Lakes, NJ, USA) were consecutively received in April 2012 (during the dry season) for routine biological monitoring at the reference laboratory of the hôpital de la Liberté, N'Djamena, an institutional reference laboratory devoted to HIV screening and monitoring. Two aliquots of one sample were kept at ambient temperature. No extra specimens were required. All blood samples were unlinked to identifiers. Each aliquot was first subjected to immediate measurement by flow cytometry reference analyzer, at ambient temperature at the hôpital de la Liberté, N'Djamena, and the second aliquot was sent within 4 hours to the hôpital Militaire D'Instruction, N'Djamena, for CD4 T cell count by Auto40 flow cytometer.

The study was approved by the Chad Ministry of Public Health. Written informed consents from all subjects were obtained before study initiation. For children samples, legal children's guardians or parents signed an informed consent. 


\section{CD4 T cell quantification and validation of the Auto40 flow cytometer comparing with the FACSCalibur reference flow cytometry method}

CD4 $\mathrm{T}$ cell quantification was performed in parallel on 2 different flow cytometers: (1) the FACSCalibur [Becton Dickinson Immuno-cytometry System (BDIS), San Jose, CA, USA], a dedicated clinical reference flow cytometer for CD4 $\mathrm{T}$ cell counting installed at the hôpital de la Liberté, N'Djamena, using Multitest reagent (BDIS) and MultiSet V2.2 software (BDIS) for calculating the absolute and percentage values of CD4 $\mathrm{T}$ cells according to the manufacturer instructions, as previously described $[22,23]$; and (2) the Auto40 flow cytometer (Apogee Flow Systems Ltd) equipped with a green laser at $532 \mathrm{~nm}$, a side scatter detector, two fluorescence channels and means for direct volumetric counting, without requiring a red blood cell lysis step.

Direct volumetric CD4 T cell measurements were performed on the Auto40 using phycoerythrin (PE)conjugated anti-CD4 and PE-Dyomics649-conjugated
anti-CD45 monoclonal antibodies (Apogee Flow Systems Ltd). The Auto40 analytical procedure avoids the need for a wash step. Briefly, $50 \mu \mathrm{l}$ of whole EDTA-blood was added into polypropylene test tubes containing predispensed, stabilized monoclonal antibodies. After $25 \mathrm{mi}-$ nutes of incubation at room temperature in the dark, the blood samples were diluted 1:10 in phosphate buffered saline. The no-lyse-no-wash stained samples were run on the Auto40 flow cytometer, and CD4 T cell count was obtained in absolute number and in percentage. Analysis on the Auto40 flow cytometer was automatically performed by the built-in software "Auto-lymphocyte" (Apogee Flow Systems Ltd), with the possibility of controlling and assessing the quality of the data analysis. CD45-positive lymphocytes and monocytes were identified by primary gating on bright CD45 fluorescent cells in a CD45xside scatter dot plot scatter gram (Figure 1A). The CD45 fluorescent polymorphonuclear cells were excluded from the gating according to their high nuclear density. Within the CD45-positive cells, CD4-positive
A

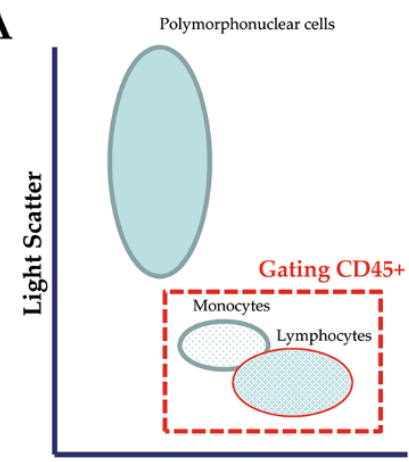

CD45-PE-Dyomics649

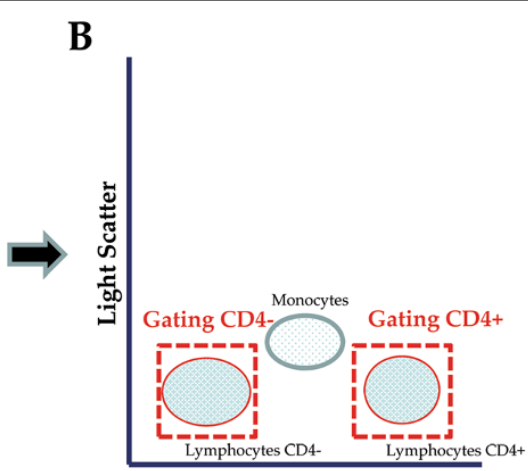

CD4-PE

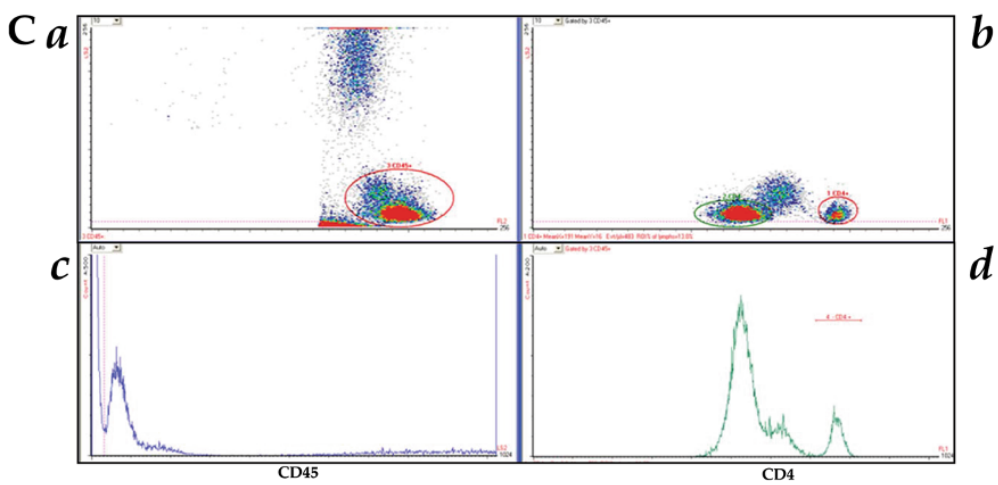

Figure 1 Gating strategy for volumetric, CD45-assisted panleucogating Auto40 flow cytometer (Apogee Flow Systems Ltd, Hemel Hempstead, UK), as depicted from typical figure provided by "Auto-Lymphocyte" software (Apogee Flow Systems Ltd) for the counting of CD4 T lymphocytes: A. CD45-PE-Dyomics649 x axis-light scatter dot plot scattergram; the primary CD45 gating differentiates clearly the CD45-positive lymphocytes and monocyte populations, and the population of polymorphonuclear cells; B. CD4-PE $x$ axis-light scatter dot plot scattergram; double secondary CD4 gatings allow counting independently the population of CD4-negative lymphocyte and CD4-positive lymphocytes; $\mathbf{C}$. Representative figure depicted by the software "Auto-Lymphocyte" in one blood sample taken as example: (a) CD45 (FL2)xside scatter (LS2) dot plot scattergram; (b) CD4 (FL1)xside scatter (LS2) dot plot scattergram; (c) Distribution of bright CD45 events during blood sample counting; (d) Distribution of bright CD4 events within the primary CD45 gating scattergram, during blood sample counting. 
and CD4-negative lymphocytes were identified by secondary gating in a CD4xside scatter dot plot scatter gram (Figure 1B). CD4-positive $\mathrm{T}$ lymphocytes are easily separated for monocytes and CD4-negative lymphocytes, and counted independently. The CD4 T lymphocytes count in absolute number corresponds to the CD4positive secondary CD4 gating cell populations. The CD4 T lymphocytes count in percentage corresponds to the ratio of CD4-positive lymphocytes count in absolute number to the total CD4-positive and CD4-negative lymphocytes counts, corresponding to the sum of both secondary CD4 gating. The sample reading takes around 2 minutes. Aside from simplifying sample preparation, the software "Auto-lymphocyte" allows automatic reading, and greatly facilitates manipulations by laboratory technicians. The whole procedure is fast and only needs 30 minutes to be completed. According to the manufacturer, the Auto40 flow cytometer has the theoritical capacity of $150 \mathrm{CD} 4 \mathrm{~T}$ cells enumerations per day.

To ensure quality control of the flow cytometric immune-phenotyping method with regard to the performance of the personnel and the instrument, the same lots of reagents were used throughout the study, and all sample preparations and flow cytometric analyses were performed by the same operator for each instrument, as previously reported [24]. Adequate training on the use of reverse pipetting technique and electronic pipette was also provided for each operator. Furthermore, the FACSCalibur photomultiplier tube voltage, sensitivity, and fluorescent compensation settings were optimized prior to sample acquisition. In addition, weekly calibration and internal quality control of the FACSCalibur were performed by using Calibrite beads (BDIS) and FACSComp software (BDIS). Quality control on the Auto40 flow cytometer was primarily assessed by the use of a calibrated bead sample (Apogee cat \# 1444 for Auto40-green, Apogee Flow Systems Ltd) at the beginning and end of each session, and on the use of stabilized blood reference samples (Cytofix CD4, CaltagMedsystems Ltd, UK) as an additional external control.

\section{Statistical analyses}

The Method Validator software version 1.1.9.0. (Philippe Marquis, France) and the SAS-PC software (version 8.2, SAS Institute, Cary, North Carolina, USA) were used for statistical analyses. First, correlations between the absolute $\mathrm{CD} 4 \mathrm{~T}$ cell counts obtained by the reference FACSCalibur and the Auto40 were established by the Passing-Bablok nonparametric method [25]. Secondly, the agreement between FACSCalibur and Auto40 was depicted by difference plots as proposed by Bland and Altman [25-27] and Pollock et al. [28]. The BlandAltman and Pollock analyses were carried out to calculate the mean of absolute and relative bias and limits of agreement, respectively, corresponding to the 95\% confidence intervals $[ \pm 1.96 \times$ standard deviation (SD)] of the mean absolute and relative bias of all paired measurements [27].

To assess the clinical impact of using the Auto40 instead of the FACSCalibur in Chad setting, the sensitivity and the specificity of the Auto40 was calculated to identify patients who had with the FACSCalibur a CD4 T cell count below $200 \mathrm{cells} / \mu \mathrm{l}$, the threshold of immunerestoration under ART and the threshold for therapeutic initiation according to the 2006-revised WHO recommendations (WHO, 2007), 350 cells/ $\mu \mathrm{l}$, the new threshold for ART initiation for adults and children aged more than 5 years according to the 2010-revised WHO guidelines [2], or 750 cells $/ \mu$ l and\%CD4+ $\leq 25 \%$, the new absolute and percent CD4 T cell count WHO thresholds for ART initiation in children aged between 24 and 59 months [2]. For clinical significance of the measurement differences on treatment decision, the Cohen's $k$ coefficient was calculated on study population [29].

\section{Results}

\section{Accuracy of direct volumetric CD4 T cell measurements} by the Auto40 flow cytometer in Chad

A total of 258 EDTA-blood samples with correct preanalytical preparation were obtained from 182 HIV-1infected adults (median age, 33.3 years; range, 18-59, 60 males), and 76 HIV-1-infected children older than 5 years (median age, 6.2 years; range, 5-17, 35 males). The majority of study patients (74\%) were taking ART according to the WHO recommendations for resourcelimited settings, whereas $26 \%$ of them were naïve for ART. No pregnant woman was included in the study.

The absolute and relative bias (and the limits of agreement) for CD4 $\mathrm{T}$ cell counting in absolute count and percentage are shown in Table 1 for the study in adults and children, by the Apogee Auto40 flow cytometer and the FACSCalibur, and in Table 2 at various CD4 T cell count ranges. In addition, the Figure 2 depicts the Passing-Bablok agreement test and the Bland-Altman analyses between the CD4 T cell count results obtained by Auto40 and FACSCalibur flow cytometers, in absolute number and in percentage, in the 182 study HIV-1infected adults and 76 HIV-1-infected children older than 5 years.

Mean \pm SD of CD4 T cells $/ \mu$ l expressed in absolute number was $864 \pm 761 \mathrm{cells} / \mu \mathrm{l}$ (range, $5-5639$ ) by Auto40 flow cytometer, and $975 \pm 765$ cells $/ \mu$ l (range, 5-5674) by FACSCalibur ( $>$ > 0.5). The non-parametric Passing-Bablok regression analysis on all 258 available $\mathrm{T}$ cell results expressed in absolute count revealed a high correlation between CD4 $\mathrm{T}$ cell counts obtained by Auto40 flow cytometer and FACSCalibur $(r=0.99)$ with 
Table 1 CD4 T cell counting in absolute cells/ $\mu$ land percentage in 182 HIV-1-infected adults and 76 HIV-1-infected children older than 5 years, by the Apogee Auto40 flow cytometer at the hôpital Militaire D'Instruction, N'Djamena, Chad, and by the FACSCalibur at the hôpital de la Liberté, N'Djamena

\begin{tabular}{|c|c|c|c|}
\hline \multicolumn{2}{|l|}{ Categories } & \multirow{2}{*}{$\begin{array}{l}\text { Adults } \\
\mathrm{N}=182\end{array}$} & \multirow{2}{*}{$\begin{array}{l}\text { Children } \\
N=76\end{array}$} \\
\hline Number & & & \\
\hline \multicolumn{4}{|l|}{ Absolute CD4 T cells (cells/ul) } \\
\hline Apogee Auto40 & Mean \pm SD & $627 \pm 591$ & $1432 \pm 821$ \\
\hline FACSCalibur & Mean \pm SD & $635 \pm 588$ & $1449 \pm 835$ \\
\hline Absolute bias (limits of agreement) ${ }^{a}$ & Mean $( \pm 1.96 \mathrm{SD})$ & $-16.0(-38.2 ; 6.1)$ & $30.0(-14.7 ; 88.7)$ \\
\hline Relative (\%) bias (limits of agreement) ${ }^{\mathrm{b}}$ & Mean $( \pm 1.96 \mathrm{SD})$ & $1.0(-1.8 ; 3.8)$ & $0.3(-2.2 ; 2.7)$ \\
\hline \multicolumn{4}{|l|}{ Percentage of CD4 T cells (\%CD4) } \\
\hline Apogee Auto40 & Mean \pm SD & $29.1 \pm 12.8$ & $32.1 \pm 10.1$ \\
\hline FACSCalibur & Mean \pm SD & $28.5 \pm 12.5$ & $32.3 \pm 10.6$ \\
\hline Absolute bias (limits of agreement) ${ }^{a}$ & Mean $( \pm 1.96 \mathrm{SD})$ & $-3.0(-7.1 ; 1.1)$ & $1.0(-0.4 ; 2.4)$ \\
\hline Relative (\%) bias (limits of agreement) ${ }^{\mathrm{b}}$ & Mean $( \pm 1.96 \mathrm{SD})$ & $-11.0(-25.8 ; 3.8)$ & $3.0(-1.3 ; 5.3)$ \\
\hline
\end{tabular}

${ }^{a}$ The Bland Altman analysis was carried out to calculate the absolute bias and limits of agreement which are the $95 \%$ confidence intervals ( $\pm 1.96 \times$ SD) of the mean bias of all paired measurements in a given category [27];

$\mathrm{b}$ The Pollock analysis was carried out to calculate the relative bias and limits of agreement which are the $95 \%$ confidence intervals ( $\pm 1.96 \times$ SD) of the mean bias of all paired measurements in a given category [28].

SD: Standard deviation.

a slope of 0.98 (95\% IC: $0.96-1.01)$ and an intercept of +4.4 (95\% CI: -18.0 - 26.8). The mean absolute bias measured by Bland-Altman analysis, and the mean relative bias measured by Pollock analysis, between CD4 T cells/ $\mu$ l obtained by Apogee Auto40 flow cytometer and FACSCalibur over the entire range of CD4 T cell results, were -9.4 cells $/ \mu \mathrm{l}(95 \% \mathrm{CI}$ : $-23.5-4.7)$ with limits of agreement from -15 to 93 cells $/ \mu \mathrm{l}$, and $+2.0 \%$ with limits of agreement from -0.9 to $4.9 \%$, respectively.

Mean \pm SD CD4 T cell count in percentage was $30.1 \pm$ $12.1 \% \mathrm{CD} 4+$ (range, 1-87) by Auto40 flow cytometer, and $29.6 \pm 12.1 \% C D 4+$ (range, $1-83$ ) by FACSCalibur $(\mathrm{P}>0.5)$. Results of CD4 $\mathrm{T}$ cell count in percentage by Auto40 flow cytometer and FACSCalibur were highly

Table 2 CD4 T cell counting in absolute count and percentage in 258 HIV-1-infected individuals, by the Apogee Auto40 flow cytometer at the hôpital Militaire D'Instruction, N'Djamena, Chad, and by the FACSCalibur at the hôpital de la Liberté, N'Djamena, at various CD4 T cell count ranges according to the FACSCalibur results

\begin{tabular}{|c|c|c|c|c|}
\hline Categories & & $<200$ cells $/ \mu \mathrm{l}$ & $200-350$ cells/ $\mu \mathrm{l}$ & $>350$ cells $/ \mu \mathrm{l}$ \\
\hline Number & & $N=27$ & $\mathrm{~N}=43$ & $\mathrm{~N}=188$ \\
\hline \multicolumn{5}{|l|}{ Absolute CD4 T cells $(\text { cells/ } \mu \mathrm{l})^{*}$} \\
\hline Apogee Auto40 & Mean \pm SD & $118 \pm 161$ & $278 \pm 129$ & $2990 \pm 3745$ \\
\hline FACSCalibur & Mean \pm SD & $100 \pm 135$ & $215 \pm 103$ & $3017 \pm 3756$ \\
\hline Absolute bias (limits of agreement) ${ }^{a}$ & Mean $( \pm 1.96 \mathrm{SD})$ & $-4.0(-33.8 ;+25.8)$ & $10.0(-70.0 ;+90.0)$ & $12.0(-160.7 ;+184.7)$ \\
\hline Relative (\%) bias (limits of agreement) ${ }^{\mathrm{b}}$ & Mean $( \pm 1.96 \mathrm{SD})$ & $62.0(-134.0 ;+258.0)$ & $7.0(-27.2 ;+41.2)$ & $-3.0(-12.4 ;+6.4)$ \\
\hline \multicolumn{5}{|l|}{ Percent CD4 T cells $(\% \mathrm{CD} 4)^{* *}$} \\
\hline Apogee Auto40 & Mean \pm SD & $10.0 \pm 12.7$ & $19.5 \pm 6.3$ & $55.1 \pm 44.5$ \\
\hline FACSCalibur & Mean \pm SD & $9.0 \pm 11.3$ & $18.0 \pm 4.2$ & $53.3 \pm 41.7$ \\
\hline Absolute bias (limits of agreement) ${ }^{\mathrm{a}}$ & Mean $( \pm 1.96 \mathrm{SD})$ & $1.0(-1.8 ;+3.8)$ & $2.0(-2.3 ;+6.3)$ & $2.0(-3.4 ;+7.4)$ \\
\hline Relative (\%) bias (limits of agreement) ${ }^{\mathrm{b}}$ & Mean $( \pm 1.96 \mathrm{SD})$ & $6.0(-10.3 ;+22.3)$ & $7.0(-13.2 ;+27.2)$ & $2.0(-4.6 ;+8.6)$ \\
\hline
\end{tabular}

* Results in absolute CD4 T cell counts by Auto40 and FACSCalibur were correlated using the non-parametric Passing-Bablok regression analysis $(<200$ cells/ $\mu$ : $r=0.86$, slope $=1.11$, intercept $=-12.0 ; 200-350$ cells $/ \mu \mathrm{l}: r=0.68$, slope $=1.31$, intercept $=-96.5 ;>350$ cells $/ \mu \mathrm{l}: r=0.98$, slope $=1.02$, intercept $=-24.8$ );

** Results in percentage CD4 T cell counts by Auto40 and FACSCalibur were correlated using the non-parametric Passing-Bablok regression analysis (< 200 cells/ $\mu \mathrm{l}: \mathrm{r}=0.89$, slope $=1.00$, intercept $=0.0 ; 200-350$ cells $/ \mu \mathrm{l}: r=0.89$, slope $=1.00$, intercept $=0.0 ;>350$ cells $/ \mu \mathrm{l}: r=0.95$, slope $=1.00$, intercept $=0.0$ );

${ }^{\mathrm{a}}$ The Bland Altman analysis was carried out to calculate the absolute bias and limits of agreement which are the $95 \%$ confidence intervals $( \pm 1.96 \times$ SD) of the mean bias of all paired measurements in a given category [27];

${ }^{\mathrm{b}}$ The Pollock analysis was carried out to calculate the relative bias and limits of agreement which are the $95 \%$ confidence intervals ( $\pm 1.96 \times$ SD) of the mean bias of all paired measurements in a given category [28].

SD: Standard deviation. 


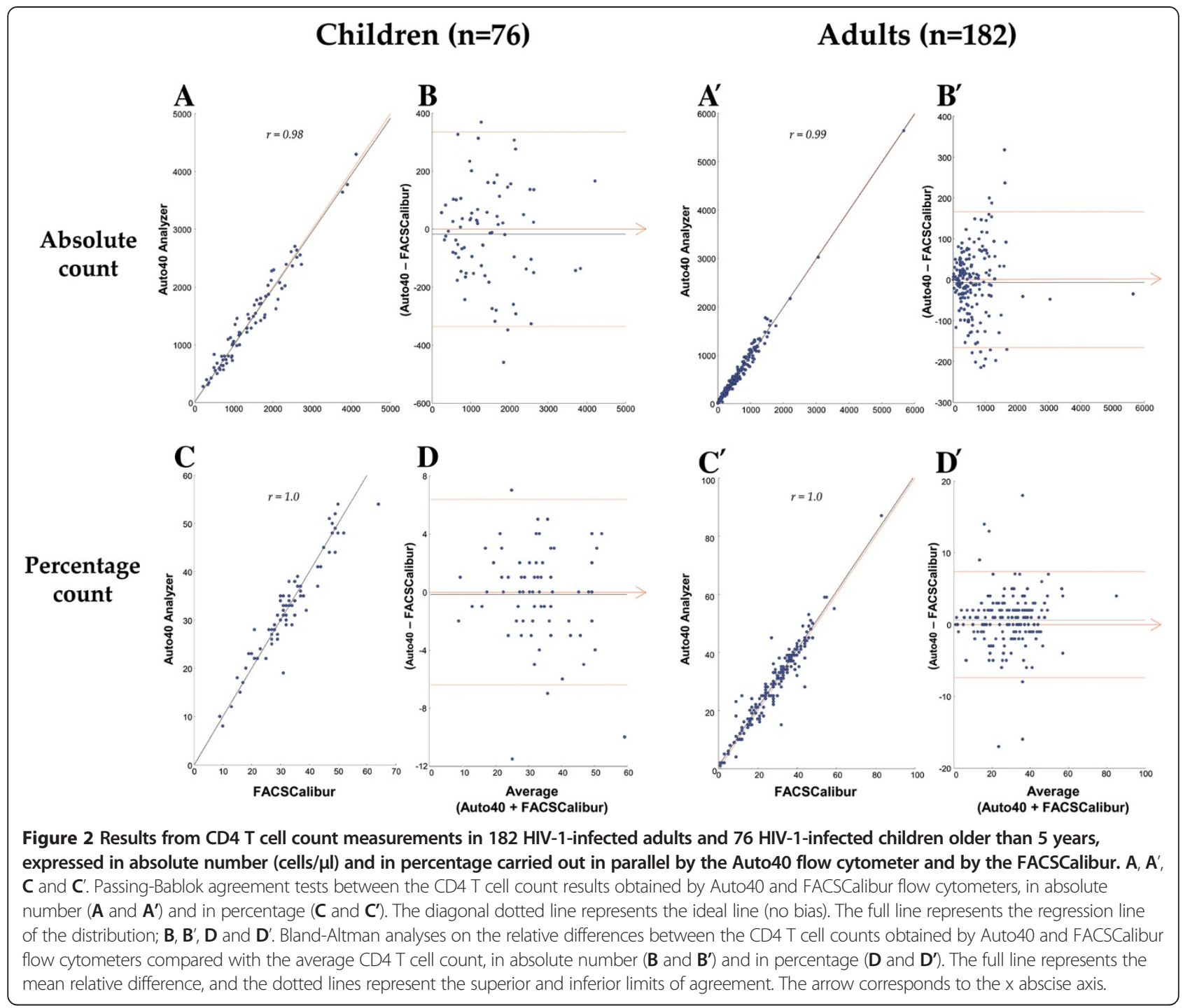

correlated by regression analysis $(\mathrm{r}=0.96)$ with a slope of 0.96 (95\% IC: $0.92-0.99$ ) and an intercept of +1.7 (95\% CI: $0.6-2.9)$. The mean of absolute bias and relative bias between percentage of CD4 T cells obtained by Auto 40 flow cytometer and FACSCalibur were $+0.4 \%$ CD4 (95\% CI: $-0.02-0.86)$ with limits of agreement from -2.4 to $0.3 \% \mathrm{CD} 4$, and $+3.0 \%$ with limits of agreement from -6.6 to $0.6 \%$, respectively.

The number of outliers showed a trend to be higher when the CD4 $\mathrm{T}$ cell count was expressed in absolute count $(16 / 258=6.2 \%)$ than when it was given in percentage $(10 / 258=3.9 \%)$, although the difference was not statistically significant ( $\mathrm{P}=0.22$ by Student $t$ test).

\section{Sensitivity and specificity to identify clinically-relevant thresholds by the Auto40 flow cytometer}

The sensitivity and specificity of CD4 T cell counting by the Auto40 flow cytometer to identify the patients with less or more than $200 \mathrm{CD} 4 \mathrm{~T}$ cells/ $\mu \mathrm{l}, 350 \mathrm{CD} 4 \mathrm{~T}$ cells/ $\mu \mathrm{l}, 750 \mathrm{CD} 4 \mathrm{~T}$ cells $/ \mu \mathrm{l}$ and $25 \% \mathrm{CD} 4+$, were calculated on the 258 available CD4 T cell count measurements, and are depicted in the Table 3. Whatever the thresholds considered, the concordance between the Auto40 flow cytometer and FACSCalibur methods was high, and the decision did not differ between study blood samples according to both methods ( $\mathrm{K}=0.96$ to 0.98 ; $\mathrm{P}<0.01$ ).

\section{Discussion}

In the present study, we carried out a new evaluation of the biological performances of the Auto 40 flow cytometer in Chad focusing on the HIV-infected adult and children populations, independently of the manufacturer, and in complement to those previously reported in Senegal [15] and Cameroon [19]. Indeed, several evaluations by at least 3 independent laboratories in the field are strongly recommended for effective validation of the 
Table 3 The sensitivity and specificity of CD4 T cell counting by the Auto40 to identify patients having less than

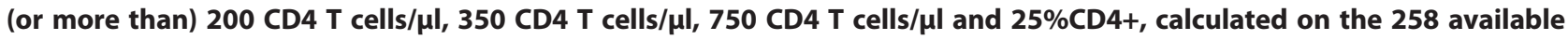
CD4 T cell count measurements

\begin{tabular}{|c|c|c|c|c|}
\hline & & Sensitivity & Specificity & Cohen's k coefficient \\
\hline & 200 CD4 T cells/ $\left.\mu\right|^{*}$ & $89 \%$ & $99 \%$ & 0.97 \\
\hline \multirow[t]{3}{*}{ Thresholds } & 350 CD4 T cells/ $\left.\mu\right|^{* *}$ & $94 \%$ & $98 \%$ & 0.98 \\
\hline & 750 CD4 T cells/ $\mu l^{* * *}$ & $99 \%$ & $96 \%$ & 0.97 \\
\hline & $25 \% C D 4$ & $94 \%$ & $98 \%$ & 0.96 \\
\hline
\end{tabular}

* 200 CD4 T cells/ $\mu$ l: Threshold of immune-restoration under antiretroviral treatment and the threshold for therapeutic initiation according to the 2006-revised WHO recommendations [30];

** 350 CD4 T cells/ $\mu$ l: New WHO threshold for antiretroviral treatment initiation in adults and children aged more than 5 years [3];

*** $750 \mathrm{CD} 4 \mathrm{~T}$ cells/ $\mu \mathrm{l}$ and 25\%CD4+: WHO thresholds for antiretroviral treatment initiation in children aged between 24 and 59 months [2];

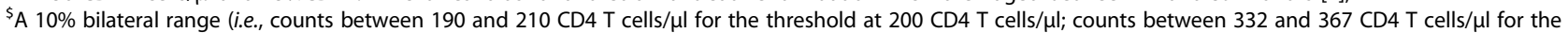

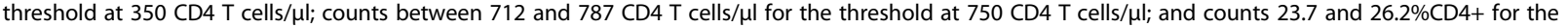
threshold at $25 \% \mathrm{CD} 4+$ ) were considered similar.

newly introduced affordable CD4 T cell measurement technologies to be used in resources-constrained settings $[6,21]$. Our results confirm that the Auto40 flow cytometer, whether operated in the field in Chad by a laboratory technician, has an acceptable performance compared with the FACSCalibur for CD4 T cell quantification expressed in absolute number as well as in percentage in HIV-infected adult and children patients. The Auto40 flow cytometer results in absolute number and percentage which gave high correlations with those obtained by the reference flow cytometer method. The correlation was maintained at different $\mathrm{CD} 4 \mathrm{~T}$ cell count ranges over all the dynamic range of values in absolute number (until $5639 \mathrm{CD} 4 \mathrm{~T}$ cells/ $\mu \mathrm{l}$ ) as well as in percentage (until $83 \% \mathrm{CD} 4+$ ). CD4 $\mathrm{T}$ cell counting by CD45-assisted Auto40 allowed to identify the majority of adults with CD4 T cells below 200 cells/ $\mu$ l or 350 cells/ $\mu \mathrm{l}$, and of children below 750 cells $/ \mu \mathrm{l}$ or $25 \% \mathrm{CD} 4+$, demonstrating the capacity of Auto40 to accurately assess the major thresholds in absolute number (200 cells/ $\mu \mathrm{l}, 350$ cells $/ \mu \mathrm{l}$ and 750 cells $/ \mu \mathrm{l})$ or in percentage $(25 \%$ $\mathrm{CD} 4+$ ), used in clinical practice to initiate or follow ART in adults and children. Taken together, these findings demonstrate that the simplified, single-platform, volumetric, CD45-assisted pan-leucogating Auto40 flow cytometer is a reliable alternative flow cytometer for $\mathrm{CD} 4 \mathrm{~T}$ lymphocyte enumeration to be used in routine for immunological monitoring according to the 2010revised WHO recommendations in HIV-infected adults as well as children living in resource-constrained settings.

Our study confirms and extends the interest of the Auto40 analyzer for CD4 T cell enumeration in developing countries, as recently reported in Senegal by Dieye et al. [15], and in Cameroon by Mbopi-Kéou et al. [20]. The Senegalese validation used the initial Auto40 version based on primary CD4 gating and focused exclusively on $\mathrm{CD} 4 \mathrm{~T}$ cell counting in absolute number [15]. However, as the percentage of CD4 T cells is essential for monitoring HIV disease progression in children less than 5 years $[2,14]$, the primary CD4 gating format of the Auto40 analyzer that only measure absolute CD4 T cell numbers, was being modified by the manufacturer in 2006 to measure the percentage CD4 T cells. Thus, our observations extent the previous study in Senegal, by demonstrating that the updated version of the Auto40 flow cytometer, now based on a pan-leucogating protocol using anti-CD45 and anti-CD4 monoclonal antibodies, is not only valid for CD4 T cell enumeration in absolute number, but also in percentage. Finally, the present validation of the Auto40 analyzer in Chad reinforces and improves the previous Senegalese and Cameroonese conclusions on the clinical interest of the Auto40 flow cytometer for immunological monitoring of HIV-infected adult and children. The present study however was conducted under controlled conditions in a reference laboratory and by qualified technicians. Further studies are needed to confirm the reliability of the Auto40 analyzer for routine usage in the field.

Immunophenotyping by flow cytometry is the reference method for the enumeration of the CD4 marker on $\mathrm{T}$ lymphocytes [31]. Initially, the use of large panel of reagents and stringent gating techniques for full lymphocyte subset analysis has been shown to be superfluous and expensive [32]. The simplified flow cytometric panleucogating protocol is based on a sequential strategy by initially gating on the total white blood cell population (CD45-positive population), which then serves as the common denominator to enumerate CD4-positive $\mathrm{T}$ lymphocytes instead of primarily gating on the error prone lymphocyte population [33]. The specific use of the side scatter parameter allows for the discrimination of monocytes due to the high side scatter and low CD4 expression of monocytes thereby enabling accurate CD4-positive T cell enumeration. The CD4-positive lymphocytes are low side scatter and high CD4 expressing cells [34]. The pan-leucogating method has been demonstrated to allow accurate CD4 T cell counting, when 
used in dual platforms [34-36] as well as single-platforms, either volumetric [37] or bead-based [38,39].

The performance of single-platform, volumetric flow cytometric systems operating with CD45-based gating and generic monoclonal antibodies has been previously reported for a limited number of commercially available analyzers, including mainly the microcapillary-based Guava AutoCD4/CD4\% ${ }^{\mathrm{Tm}}$ (Merck Millipore LS International Hayward, CA, USA) [24] and the CyFlow SL_3 ${ }^{\text {tm }}$ (Partec $\mathrm{GmbH}$, Munster, Germany) [40]. Both latter analyzers have proven their usefulness for validated absolute and percentage of CD4 $\mathrm{T}$ cell counting in the field $[24,40]$. These single-platforms using only a flow cytometer and volumetric systems allow counting CD4 T cells in a fixed volume, thus leading to a considerable reduction in the costs of CD4-positive $\mathrm{T}$ cell enumeration by comparison to microbead-based systems [31]. In addition, the compact low-range single-platforms Auto40 and CyFlow SL_3 $3^{\text {tw }}$ are portable desk-top flow cytometers that does not require optical alignment, can run on a 12-volt car battery, and can be connected to a laptop computer, suggesting their possible use in health care mobile unit that could make CD4 T cell enumeration available in remote or hard-to-reach locations, as previously shown for the Auto 40 flow cytometer installed in health mobile unit in Cameroon [20]. These observations raise the issue of decentralization of immunological monitoring in large areas where laboratories are remote, using health mobile units capable of performing screening and immunological monitoring of HIV-infected patients [20,41].

One of the additional main features of the Auto40 analyzer is the use of stabilized monoclonal antibodies. The assay reagents can be stored for prolonged period of time (up to 12 months) at high temperature without any loss of biological activity [42]. The use of thermoresistant reagents allowed reliable measurements of CD4 $\mathrm{T}$ cell count, both in absolute and percentage terms, under unfavourable conditions like high temperatures in the tropics, as in remote areas where the conditions met for the storage of reagents (cold chain), particularly during shipment and delivery, is not guaranteed [43]. The thermo-stable monoclonal antibodies used in the present study can be kept for as long as one year at room temperature, i.e. $30^{\circ} \mathrm{C}$, and has been chosen for all laboratories equipped by an Auto40 flow cytometer in Chad. The possibility of long-term storage of reagents at room temperature for one year should facilitate the planning of laboratory activities and reduce the costs related to loss of reagents stability. Overall, the use of thermo-stable reagents increases the accessibility to flow cytometry testing. However, while the manufacturing costs related to the antibody stabilization procedure does not exceed $15 \%$ of the original cost [42], the final sale prices of thermo-resistant reagents marketed by Inodia
(France) is higher than $40 \%$ compared to those of liquid reagents.

In the present study, all specimens used for the evaluation were fresh and not travelled. This practice represents the current situation in Chad. Indeed, there is no organization of blood samples transportation thorough the country, mainly because of heavy logistical constrained in a very large country, which is furthermore affected by a hard tropical climate. In contrast, the socalled "Conseil National de Lutte contre le SIDA", N'Djamena, Chad decided to decentralize the CD4 analyzers, and acquired from 2003 to 2012 around twenty CD4 analyzers to be installed in laboratory facilities thorough the country.

The accurate determination of CD4 T cells is of crucial clinical importance for caring adults or children infected with HIV or suffering from AIDS. Although classical flow cytometry represents the reference method for CD4 $\mathrm{T}$ cell enumeration, the feasibility of flow cytometric methods in the field remains controversial in resourcepoor settings [8]. In the Cameroonese experience, welltrained technicians were able to use the Auto40 flow cytometer with low intra- and inter- run precisions ranging from $4.8 \%$ to $5.5 \%$ and from $5.3 \%$ to $7.9 \%$, respectively, thus less than $10 \%[19,20]$, considered as acceptable for routine clinical practice [15], and comparable to other published reports using single-platform flow cytometers $[10,24,40,44]$. The low observed variability of the Auto 40 flow cytometer confirmed that singleplatform flow cytometric methods are more reproducible than dual-platform [45]. Higher precisions for high than for low CD4 T cell count have been previously reported with single-platform volumetric flow cytometric method [40]. Finally, the Auto40 system showed a high capacity of accurately discriminate CD4 $\mathrm{T}$ cell values around the relevant $\mathrm{CD} 4 \mathrm{~T}$ cells thresholds recommended by the 2010-revised WHO guidelines to initiate and follow ART in HIV-infected adults or children, as previously reported $[15,19,46]$.

\section{Conclusions}

In conclusions, the Auto40 flow cytometer constitutes a promising system for performing single-platform absolute and percent CD4 $\mathrm{T}$ lymphocyte counts with excellent reproducibility, and should facilitate wider access to CD4 $\mathrm{T}$ cell enumeration for adults and children infected with HIV infection living in resourceconstrained countries.

Competing interests

The authors declare that they have no competing interests.

Authors' contributions

DK, ANM and LB conceived and designed the research, and analyzed the results, performed the statistical analyses and drafted the manuscript with 
MAJ; DK and NN have performed the experiments; BD was directly involved in the implementation of Auto 40 analyzers in Chad; NDO discussed the medical validity of CD4 T counting by the Auto 40 analyzer. All authors read and approved the final manuscript.

\section{Acknowledgments}

The authors are grateful to the hôpital d'Instruction des Armées, N'Djamena, Chad, for making this evaluation possible and to the hôpital de la Liberté, N'Djamena, for performing the analyses on the FACSCalibur. We thank Hota Mathieu for hepful technical assistance. The study was carried out completely independently of the Auto40 manufacturer. Dr. M.A. Jenabian is supported by a CANFAR/CTN Postdoctoral Fellowship Award.

\section{Author details}

${ }^{1}$ Ministère de la Santé Publique, N'Djamena BP 407, Chad. ${ }^{2}$ Chronic Viral IIIness Service and Research Institute of the McGill University Health Centre, Montreal, Canada. ${ }^{3}$ Hôpital de la Liberté, N'Djamena, Chad. ${ }^{4}$ Conseil National de Lutte contre le SIDA, Primature, N'Djamena, Chad. ${ }^{5}$ Organisation Mondiale de la Santé, Représentation du Tchad, N'Djamena, Chad. 'aboratoire National de Référence des Maladies Sexuellement Transmissibles et du SIDA, Département de Microbiologie, Faculté de Médecine de Libreville, Université des Sciences de la Santé, Libreville, Gabon. ’Laboratoire de virologie, hôpital Européen Georges Pompidou, and Faculté de Médecine Paris Descartes, Université Paris Descartes (Paris V), Sorbonne Paris Cité Paris, France.

Received: 10 October 2012 Accepted: 25 April 2013

Published: 30 April 2013

\section{References}

1. UNAIDS: Global report on the global AIDS epidemic. 2010. Available at http:// www.unaids.org/globalreport/global_report.htm.

2. World Health Organization: World Health Organization (WHO) recommendations. Antiretroviral therapy for HIV infection in infants and children: toward universal access. 2010. http://whqlibdoc.who.int/ publications/2010/9789241599801_eng.pdf.

3. World Health Organization: World Health Organization (WHO) recommendations antiretroviral therapy for HIV infection in adults and adolescents. Antiretroviral therapy for a public health approach 2010 revision. 2010. http://whalibdoc.who.int/publications/2010/9789241599764_eng.pdf.

4. Belec L, Bonn JP: Challenges in implementing HIV laboratory monitoring in resource-constrained settings: how to do more with less. Future Microbiol 2011, 6(11):1251-1260.

5. Belec L, Mbopi-Keou FX, Gershy-Damet GM, Mboup S: HIV laboratory monitoring for effective ART in Africa. Lancet Infect Dis 2012, 12(6):430.

6. Mandy F, Janossy G, Bergeron M, Pilon R, Faucher S: Affordable CD4 T-cell enumeration for resource-limited regions: a status report for 2008. Cytometry B Clin Cytom 2008, 74(Suppl 1):S27-S39.

7. Murtagh MM: UNITAIDS Technical Report. HIV/AIDS diagnostic landscape. 2011. http://www.unitaid.eu/images/marketdynamics/publications/ unitaid_md_technical_report_diagnostics_landscape_web.pdf.

8. Jani IV, Sitoe NE, Chongo PL, Alfai ER, Quevedo Jl, Tobaiwa O, Lehe JD, Peter TF: Accurate CD4 T-cell enumeration and antiretroviral drug toxicity monitoring in primary healthcare clinics using point-of-care testing. AIDS 2011, 25(6):807-812

9. Miller CM, Ketlhapile M, Rybasack-Smith H, Rosen S: Why are antiretroviral treatment patients lost to follow-up? A qualitative study from South Africa. Trop Med Int Health 2010, 15(Suppl 1):48-54

10. Lynen L, Teav S, Vereecken C, De Munter P, An S, Jacques G, Kestens L: Validation of primary $\mathrm{CD} 4$ gating as an affordable strategy for absolute $\mathrm{CD} 4$ counting in Cambodia. J Acquir Immune Defic Syndr 2006, 43(2):179-185.

11. Miiro G, Nakubulwa S, Watera C, Munderi P, Floyd S, Grosskurth H: Evaluation of affordable screening markers to detect CD4+ T-cell counts below 200 cells/mul among HIV-1-infected Ugandan adults. Trop Med Int Health 2010, 15(4):396-404.

12. Peter TF, Shimada Y, Freeman RR, Ncube BN, Khine AA, Murtagh MM: The need for standardization in laboratory networks. Am J Clin Pathol 2009, 131(6):867-874.

13. Dieye TN, Vereecken C, Diallo AA, Ondoa P, Diaw PA, Camara M, Karam F, Mboup S, Kestens L: Absolute CD4 T-cell counting in resource-poor settings: direct volumetric measurements versus bead-based clinical flow cytometry instruments. J Acquir Immune Defic Syndr 2005, 39(1):32-37.
14. O'Gorman MR, Zijenah LS: CD4 T cell measurements in the management of antiretroviral therapy-A review with an emphasis on pediatric HIVinfected patients. Cytometry B Clin Cytom 2008, 74(Suppl 1):S19-S26.

15. Dieye TN, Diaw PA, Daneau G, Wade D, Sylla Niang M, Camara M, Diallo AA, Toure Kane C, Diop Ndiaye $H$, Mbengue B, et al: Evaluation of a flow cytometry method for CD4 T cell enumeration based on volumetric primary CD4 gating using thermoresistant reagents. I Immunol Methods 2011, 372(1-2):7-13.

16. Hoffman RA, Kung PC, Hansen WP, Goldstein G: Simple and rapid measurement of human $T$ lymphocytes and their subclasses in peripheral blood. Proc Natl Acad Sci USA 1980, 77(8):4914-4917.

17. Brando B, Barnett D, Janossy G, Mandy F, Autran B, Rothe G, Scarpati B, D'Avanzo G, D'Hautcourt JL, Lenkei R, et al: Cytofluorometric methods for assessing absolute numbers of cell subsets in blood. European Working Group on Clinical Cell Analysis. Cytometry 2000, 42(6):327-346.

18. Mercolino TJ, Connelly MC, Meyer EJ, Knight MD, Parker JW, Stelzer GT, DeChirico G: Immunologic differentiation of absolute lymphocyte count with an integrated flow cytometric system: a new concept for absolute T cell subset determinations. Cytometry 1995, 22(1):48-59.

19. Mbopi-Keou FX, Mion S, Sagnia B, Belec L: Validation of a single-platform, volumetric, CD45-assisted PanLeucogating Auto40 flow cytometer to determine the absolute number and percentages of CD4 T cells in resource-constrained settings using Cameroonian patients' samples. Clin Vaccine Immunol 2012, 19(4):609-615.

20. Mbopi-Keou FX, Sagnia B, Ngogang J, Angwafo FF 3rd, Colizzi V, Montagnier L, Belec L: Validation of a single-platform, volumetric, flow cytometry for CD4 T cell count monitoring in therapeutic mobile unit. J Trans/ Med 2012, 10:22.

21. World Health Organization: World Health Organization (WHO) Consultation on Technical and Operational Recommendations for Scale-Up of Laboratory Services and Monitoring HIV Antiretroviral Therapy in Resource-Limited Settings (13-15 December 2004: Geneva, Switzerland). 2005. http://www.who.int/hiv/ pub/meetingreports/labmeetingreport.pdf.

22. Sagnia B, Ateba Ndongo F, Ndiang Moyo Tetang S, Ndongo Torimiro J, Cairo C, Domkam I, Agbor G, Mve E, Tocke O, Fouda E, et al: Reference values of lymphocyte subsets in healthy, HIV-negative children in Cameroon. Clin Vaccine Immunol 2011, 18(5):790-795.

23. Schnizlein-Bick CT, Spritzler J, Wilkening CL, Nicholson JK, O'Gorman MR: Evaluation of TruCount absolute-count tubes for determining CD4 and CD8 cell numbers in human immunodeficiency virus-positive adults. Site Investigators and The NIAID DAIDS New Technologies Evaluation Group. Clin Diagn Lab Immunol 2000, 7(3):336-343.

24. Pattanapanyasat K, Phuang-Ngern Y, Sukapirom K, Lerdwana S, Thepthai C, Tassaneetrithep B: Comparison of 5 flow cytometric immunophenotyping systems for absolute CD4+ T-lymphocyte counts in HIV-1-infected patients living in resource-limited settings. J Acquir Immune Defic Syndr 2008, 49(4):339-347.

25. Passing H, Bablok: A new biometrical procedure for testing the equality of measurements from two different analytical methods. Application of linear regression procedures for method comparison studies in clinical chemistry, Part I. J Clin Chem Clin Biochem 1983, 21(11):709-720.

26. Bland JM, Altman DG: Statistical methods for assessing agreement between two methods of clinical measurement. Lancet 1986, 1(8476):307-310.

27. Bland $\mathrm{JM}$, Altman DG: Measuring agreement in method comparison studies. Stat Methods Med Res 1999, 8(2):135-160.

28. Pollock MA, Jefferson SG, Kane JW, Lomax K, MacKinnon G, Winnard CB: Method comparison-a different approach. Ann Clin Biochem 1992, 29(Pt 5):556-560.

29. Cohen J: A coefficient of agreement for nominal scales. Educ Psychol Meas 1960, 20:37-46.

30. World Health Organization: Antiretroviral therapy for HIV treatment of adults and adolescents: recommendations for a public health approach 2006 revision. 2007. http://www.who.int/hiv/pub/quidelines/adult/en/index.html.

31. Baum LL, Crowe S, Landay AL: Advances in CD4 cell enumeration in resource-poor countries. Curr Opin HIV AIDS 2007, 2(3):234-240.

32. Mandy FF, Nicholson JK, MCDougal JS: Guidelines for performing single-platform absolute CD4+ T-cell determinations with CD45 gating for persons infected with human immunodeficiency virus. Centers for Disease Control and Prevention. MMWR Recomm Rep 2003, 52(RR-2):1-13. 
33. Simson E, Groner W: Variability in absolute lymphocyte counts obtained by automated cell counters. Cytometry 1995, 22(1):26-34.

34. Glencross D, Scott LE, Jani IV, Barnett D, Janossy G: CD45-assisted PanLeucogating for accurate, cost-effective dual-platform CD4+ T-cell enumeration. Cytometry 2002, 50(2):69-77.

35. Pattanapanyasat K, Shain H, Noulsri E, Lerdwana S, Thepthai C, Prasertsilpa V, Likanonsakul S, Yothipitak P, Nookhai S, Eksaengsri A: A multicenter evaluation of the PanLeucogating method and the use of generic monoclonal antibody reagents for CD4 enumeration in HIV-infected patients in Thailand. Cytometry B Clin Cytom 2005, 65(1):29-36.

36. Pattanapanyasat K, Shain H, Prasertsilpa V, Noulsri E, Lerdwana S, Eksaengsri $A$ : Low cost CD4 enumeration using generic monoclonal antibody reagents and a two-color user-defined MultiSET protocol. Cytometry $B$ Clin Cytom 2006, 70(5):355-360.

37. Janossy G, Jani IV, Bradley NJ, Bikoue A, Pitfield T, Glencross DK: Affordable CD4(+)-T-cell counting by flow cytometry: CD45 gating for volumetric analysis. Clin Diagn Lab Immunol 2002, 9(5):1085-1094.

38. Sippy-Chatrani N, Marshall S, Branch S, Carmichael-Simmons K, Landis RC, Abayomi A: Performance of the Panleucogating protocol for CD4+ T cell enumeration in an HIV dedicated laboratory facility in Barbados. Cytometry B Clin Cytom 2008, 74(Suppl 1):S65-S68.

39. Storie I, Sawle A, Whitby L, Goodfellow K, Granger V, Reilly JT, Barnett D: Flow rate calibration II: a clinical evaluation study using PanLeucoGating as a single-platform protocol. Cytometry B Clin Cytom 2003, 55(1):8-13.

40. Manasa J, Musabaike H, Masimirembwa C, Burke E, Luthy R, Mudzori J: Evaluation of the Partec flow cytometer against the BD FACSCalibur system for monitoring immune responses of human immunodeficiency virus-infected patients in Zimbabwe. Clin Vaccine Immunol 2007, 14(3):293-298.

41. Mbopi-Keou FX, Ongolo-Zogo P, Angwafo F 3rd, Ndumbe PM, Belec L: High impact of mobile units for mass HIV testing in Africa. AIDS 2007, 21(14):1994-1996.

42. Barbesti S, Soldini L, Carcelain G, Guignet A, Colizzi V, Mantelli B, Corvaglia A, Tran-Minh T, Dorigatti F, Autran B, et al: A simplified flow cytometry method of CD4 and CD8 cell counting based on thermoresistant reagents: implications for large scale monitoring of HIV-infected patients in resource-limited settings. Cytometry B Clin Cytom 2005, 68(1):43-51.

43. Larsen $\mathrm{CH}$ : The fragile environments of inexpensive CD4+ T-cell enumeration in the least developed countries: strategies for accessible support. Cytometry B Clin Cytom 2008, 74(Suppl 1):S107-S116.

44. Cassens U, Gohde W, Kuling G, Groning A, Schlenke P, Lehman LG, Traore Y, Servais J, Henin Y, Reichelt D, et al: Simplified volumetric flow cytometry allows feasible and accurate determination of CD4 T lymphocytes in immunodeficient patients worldwide. Antivir Ther 2004, 9(3):395-405.

45. Reimann KA, O'Gorman MR, Spritzler J, Wilkening CL, Sabath DE, Helm K, Campbell DE: Multisite comparison of CD4 and CD8 T-lymphocyte counting by single- versus multiple-platform methodologies: evaluation of Beckman Coulter flow-count fluorospheres and the tetraONE system. The NIAID DAIDS New Technologies Evaluation Group. Clin Diagn Lab Immunol 2000, 7(3):344-351.

46. World Health Organization: Towards Universal Access Scaling up priority HIVI AIDS interventions in the health sector. 2010. Available at: http://www.who. int/hiv/pub/2010progressreport/summary_en.pdf.

\section{doi:10.1186/1756-0500-6-169}

Cite this article as: Koyalta et al: Single-platform, volumetric, CD45assisted pan-leucogating flow cytometry for CD4 T lymphocytes monitoring of HIV infection according to the WHO recommendations for resource-constrained settings. BMC Research Notes 2013 6:169.

\section{Submit your next manuscript to BioMed Central and take full advantage of:}

- Convenient online submission

- Thorough peer review

- No space constraints or color figure charges

- Immediate publication on acceptance

- Inclusion in PubMed, CAS, Scopus and Google Scholar

- Research which is freely available for redistribution

Submit your manuscript at www.biomedcentral.com/submit 